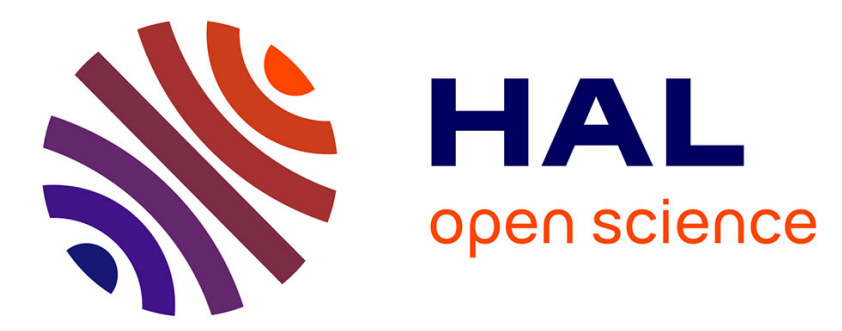

\title{
In situ spectroelectrochemical ellipsometry using super continuum white laser: Study of the anodization of magnesium alloy
}

Alexandre Zimmer, Delphine Veys-Renaux, Laurent Broch, Nicolas Stein, Emmanuel Rocca

\section{To cite this version:}

Alexandre Zimmer, Delphine Veys-Renaux, Laurent Broch, Nicolas Stein, Emmanuel Rocca. In situ spectroelectrochemical ellipsometry using super continuum white laser: Study of the anodization of magnesium alloy. Journal of Vacuum Science \& Technology B Microelectronics and Nanometer Structures, 2019, 37 (6), pp.062911. 10.1116/1.5122320 . hal-02355013

\section{HAL Id: hal-02355013 \\ https://hal.science/hal-02355013}

Submitted on 8 Nov 2019

HAL is a multi-disciplinary open access archive for the deposit and dissemination of scientific research documents, whether they are published or not. The documents may come from teaching and research institutions in France or abroad, or from public or private research centers.
L'archive ouverte pluridisciplinaire HAL, est destinée au dépôt et à la diffusion de documents scientifiques de niveau recherche, publiés ou non, émanant des établissements d'enseignement et de recherche français ou étrangers, des laboratoires publics ou privés. 


\section{In situ spectroelectrochemical ellipsometry using super continuum white laser: study of the anodization of magnesium alloy}

Running title: in situ study of the anodization of $\mathrm{Mg}$ alloy by ellipsometry

Running Authors: Zimmer et al.

Alexandre Zimmer, ${ }^{1,2, a)}$ Delphine Veys-Renaux, ${ }^{3}$ Laurent Broch, 4 Nicolas Stein ${ }^{2}$ and Emmanuel Rocca ${ }^{3}$

${ }^{1}$ Université de Bourgogne, CNRS, ICB, F-21000 DIJON, FRANCE

2Université de Lorraine, CNRS, IJL, F-57000 METZ, FRANCE

3Université de Lorraine, CNRS, IJL, F-54000 NANCY, FRANCE

${ }^{4}$ Université de Lorraine, LCP-A2MC, F-57000 METZ, FRANCE

a) Electronic mail: alex.zimmer@ellipsometrie.fr

This work shows the interest to use a real time white laser-based ellipsometer to characterize complex electrolyte | electrode interface during electrochemical process in aqueous-based medium. This method is proposed to probe electrochemical interfaces which are usually not suitable to the full extent application of ellipsometry due to great disturbance of the reflected light flux provoked by gas evolution or roughness. In situ spectroelectrochemical ellipsometry combining such a visible super continuum fiber laser-band source was not previously reported to the best of the authors' knowledge. The setup was employed to monitor an electrochemical process whose the mechanism was previously incompletely described: the pre-spark anodization regime of plasma electrolytic oxidation process of $\mathrm{Mg}$ alloy AZ91D in $3 \mathrm{M} \mathrm{KOH}$ electrolyte. Above the anodization voltage of $4 \mathrm{~V}$, the side water oxidation reaction induced light diffusion that reduces reflected light beam intensity. The process is here monitored in an extended 
voltage range from 4 to $40 \mathrm{~V}$ and in an extended spectral range $(495-800 \mathrm{~nm})$. In the presented case, the use of a visible super continuum fiber laser-band source enhanced the signal-to-noise ratio giving access to a more deeper picture of the triplex layer structure during surface repassivation by monitoring the evolution of the outer, inner and interfacial layers.

\section{INTRODUCTION}

If there is "no-one-solves-all" technique, Spectroscopic Ellipsometry (SE) can undoubtedly participate to efforts to the knowledge of a global picture of the liquid-solid interface $^{1}$ as it is the case for passive oxide on metals. ${ }^{2-9}$ It can bridge some of the inherent difficulties investigating such oxide growth mechanisms as pointed by MacDonald ${ }^{10,11}$ viz. (i) the alteration during transfer of specimens to further vacuum surface analysis techniques, (ii) the significant cost in time and money of TEM sampling and analyzing, or (iii) the multilayered structure modelling often simplified to a single one.

We have previously monitored, by in situ SE, the wet anodization of AZ91D Mg alloy in $3 \mathrm{M} \mathrm{KOH}$ medium ${ }^{12}$ in order to enhance the understanding of the subsequent sparking regime initiation of the plasma electrolytic oxidation surface treatment, ${ }^{13-17}$ beyond other established literature. ${ }^{18-20}$ In this former study only the low voltage range i.e. 0-4 V was monitored using a Xe lamp as light source due to the disturbance provoked at the interface by water-oxidation- $\mathrm{O}_{2}$ bubbles inducing light diffusion and impinging detected flux. A MgO growth at a constant rate of $0.4 \mathrm{~nm} . \mathrm{V}^{-1}$ was then highlighted. Beyond $4 \mathrm{~V}$, the study was completed by ex situ SE characterizations at three final 
voltages $(20 \mathrm{~V}, 30 \mathrm{~V}$ and $40 \mathrm{~V})$ leading to propose a global sketch of the insulating layer grown before the apparition of discharges.

This present article brings new detailed data to the aforementioned peculiar anodization mechanism through in situ SE study extended up to $40 \mathrm{~V}$, which was made possible thanks to the use of a visible supercontinuum fiber laser-based source increasing the signal-to-noise ratio of the out-coming polarized light. In addition, it was also possible to extend the spectral range fom $495 \mathrm{~nm}$ to $800 \mathrm{~nm}$ instead of the initial spectral range from $495 \mathrm{~nm}$ to $700 \mathrm{~nm}$. To the knowledge of the authors, it should be notice that the ellipsometric setup is quite original, only Miyamoto et al. recently diagnosed microstructure change in plasma facing materials using in situ reflectivity measurements based on a super continuum white laser source. ${ }^{21}$

In these conditions, SE confirms the previous general sketch and finely evidences the precipitation of the porous $\mathrm{Mg}(\mathrm{OH})_{2}$ layer above $4 \mathrm{~V}$ and the underlying repassivated $\mathrm{MgO}$ layer, from strong variations observed in the breakthrough area (4-15 V) until a smoother morphological evolution up to $40 \mathrm{~V}$.

\section{EXPERIMENTAL SETUP AND METHODOLOGY}

\section{A. Materials and sample preparation}

The AZ91D magnesium alloy supplied by Dead Sea Magnesium Ltd. (Israel) was used as substrate material with a chemical composition (wt.\%) of $\mathrm{Al} \mathrm{9,} \mathrm{Zn} \mathrm{0.7,} \mathrm{Mn} \mathrm{0.3,}$ $\mathrm{Fe}<0.005, \mathrm{Cu}<0.03, \mathrm{Si}<0.1, \mathrm{Mg}$ balance. The samples with a dimension of $c a .25 \mathrm{~mm}$ x $25 \mathrm{~mm} \times 2 \mathrm{~mm}$ were mechanically abraded with successively finer grades of $\mathrm{SiC}$ Emery papers up to 1200 and then mirror polished with silica dispersed in water (particle 
size $0.1 \mu \mathrm{m})$. They were finally rinsed with distilled water and ethanol, then finally dried in air at room temperature.

\section{B. Electrochemical and optical instrumentation}

Potentiodynamic measurements $(0-40 \mathrm{~V})$ were performed on AZ91D plates with a scan rate of $0.1 \mathrm{~V} \cdot \mathrm{s}^{-1}$, in a $\mathrm{KOH}(3 \mathrm{M})$ electrolytic solution by using a Modulab HV100 potentiostat (Solartron Analytical). In situ SE data were simultaneously acquired with the electrochemical data, using an ellipsometer based on a rotating compensator technology with a homemade coupling flow cell directly mounted on the goniometer. The coupling flow cell (Fig.1), made of PEEK, includes two quartz windows, allowing the reflection of the ellipsometer beam on the working electrode surface $\left(1 \mathrm{~cm}^{2}\right)$, in a vertical mode. The ca. 40-ml flow cell also contains a platinum grid counter-electrode facing the working plate, and a reference electrode of $\mathrm{KCl}$ saturated calomel electrode (SCE). The renewal of the electrolyte in the cell is assured with MARPRENE ${ }^{\circledR}$ tubes connected to both inlet and outlet via two peristaltic pumps (Model 323E, Watson Marlow). The in-coming beam consists of a supercontinuum fiber laser-based source (Model SM-30-UV, Leukos), and the out-coming beam is split into two perpendicularly polarized waves and simultaneously analyzed by two CCD detectors, which are synchronized, providing final spectrum of averaged ellipsometric angles $\Psi(\lambda)$ and $\Delta(\lambda)$, free of systematic errors. More details can be found elsewhere. ${ }^{22}$ For each monitoring, $(\Psi(\lambda), \Delta(\lambda))$ are measured in the spectral range 495-800 $\mathrm{nm}$ according an integration time of $0.39 \mathrm{~s}$. The optical measurements are performed at angle of incidence of $66^{\circ}$. In addition, the reflected light intensity can be calculated from the ellipsometric signal (see Ref. 5). All the electrochemical data are simultaneously recorded and synchronized with the optical ones 
through a dedicated acquisition board. All the experiments are conducted at room temperature $\left(24^{\circ} \mathrm{C}\right)$.

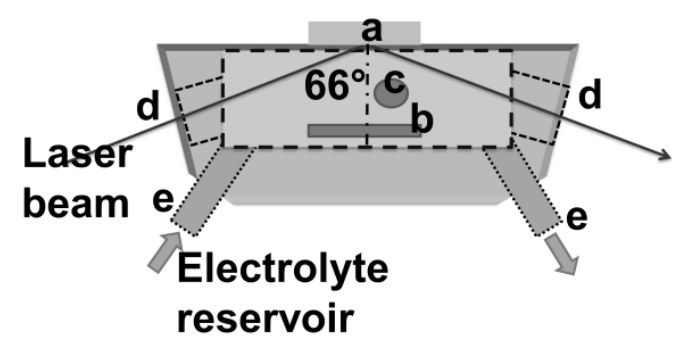

FIG. 1. Top-view scheme of the coupling flow cell used for the electrochemical anodization at high voltage in $\mathrm{KOH}$ electrolyte in a three electrodes configuration: the working electrode (a), the counter electrode (b) and the reference electrode (c). Visible supercontinuum laser beam enters and leaves the cell through quartz windows (d). Electrolyte circulation enters and leaves the cell through inlet and outlet (e).

\section{MODELLING}

\section{A. Ellipsometry}

SE measures the changes in the polarization state between incident and reflected light on the sample. ${ }^{23}$ The measured values are the angles $(\Psi, \Delta)$ related to the ratio of the Fresnel amplitude reflection coefficients of the sample by fundamental equation:

$$
r_{p} / r_{s}=\tan \psi e^{j \Delta}(1)
$$

with p- and s-polarized light in the plane of incidence and perpendicular to the plane of incidence, respectively. The parameters of the optical models were determined by minimizing the unweighted mean square error $\left(\chi^{2}\right)$ defined as: 


$$
\chi^{2}=\frac{1}{N-1} \sum_{i=1}^{N}\left[\left(\Psi_{i}^{c}(\lambda)-\Psi_{i}^{e}(\lambda)\right)^{2}+\left(\Delta_{i}^{c}(\lambda)-\Delta_{i}^{e}(\lambda)\right)^{2}\right]
$$

where 'c' stands for the calculated and 'e' for the experimental ellipsometric angles and $\mathrm{N}$ the number of experimental couples of data.

\section{B. Optical model}

Figure 2 shows the model used to adjust the experimental data from $4 \mathrm{~V}$ to $40 \mathrm{~V}$. The alloy substrate is covered by a native oxide film consisting of an interfacial layer (thickness $\mathrm{d}_{\text {interface}}$ ) covered by a dense and pure magnesium oxide layer (thickness $\mathrm{d}_{\mathrm{MgO}}$ ). The interfacial layer is composed by mixing a $\mathrm{f}_{\mathrm{MgO}} \% \mathrm{MgO}$ compound and (1- $\left.\mathrm{f}_{\mathrm{MgO}}\right)$ \%AZ91D alloy, where $\mathrm{f}_{\mathrm{MgO}}$ is the fitted volume fraction of $\mathrm{MgO}$ in the interfacial layer. The effective dielectric function of this composite layer, noted Einterface is modelled using the EMA based on the Bruggeman's model following the second-order equation:

$$
0=f_{\mathrm{MgO}} \frac{\varepsilon_{\mathrm{MgO}}(\lambda)-\varepsilon_{\text {interface }}(\lambda)}{\varepsilon_{\mathrm{MgO}}(\lambda)+2 \varepsilon_{\text {interface }}(\lambda)}+\left(1-\mathrm{f}_{\mathrm{MgO}}\right) \frac{\varepsilon_{\mathrm{AZ} 91 \mathrm{D}}(\lambda)-\varepsilon_{\text {interface }}(\lambda)}{\varepsilon_{\mathrm{AZ91 \textrm {D }}}(\lambda)+2 \varepsilon_{\text {interface }}(\lambda)}(2)
$$

In the $495-800 \mathrm{~nm}$ wavelength range, the dielectric function of periclase $\varepsilon_{\mathrm{MgO}}(\lambda)$ was taken from literature data. ${ }^{24}$ For the substrate, the dielectric function of the AZ91D $\mathrm{Mg}$ alloy $\varepsilon_{\mathrm{AZ} 91 \mathrm{D}}(\lambda)$ was determined from variable angle spectroscopic ellipsometry measurements using a wavelength point-to-point exact numerical inversion taking into account the surface roughness. See supplementary material 1 at [URL will be inserted by AIP Publishing] for the spectra of its corresponding complex refraction index $\mathrm{N}_{\mathrm{AZ91D}}(\lambda)=\sqrt{\varepsilon_{A Z 91 D}(\lambda)}$. The dense $\mathrm{MgO}$ layer is modelled with the aforementioned dielectric function $\varepsilon_{\mathrm{MgO}}(\lambda)$. An outer porous layer is implemented of magnesium hydroxide (thickness $d_{\mathrm{Mg}(\mathrm{OH}) 2}$ and volume fraction of $\left.\mathrm{Mg}(\mathrm{OH})_{2} \mathrm{f}_{\mathrm{Mg}(\mathrm{OH}) 2}\right)$. This additional outer EMA layer is calculated in a same way as Eq.(2) using $\varepsilon_{\text {water }}(\lambda)$ and $\varepsilon_{\mathrm{Mg}(\mathrm{OH}) 2}(\lambda){ }^{25}$ 
The dielectric function of the electrolytic medium was modelled with the dielectric function of water $^{26}, \varepsilon_{\text {water }}(\lambda)$ in the $495-800 \mathrm{~nm}$ range. $\varepsilon_{\mathrm{AZ} 91 \mathrm{D}}(\lambda), \varepsilon_{\mathrm{MgO}}(\lambda)$, $\varepsilon_{\mathrm{Mg}(\mathrm{OH}) 2}(\lambda)$ and $\varepsilon_{\text {water }}(\lambda)$ functions are considered as constant with the anodization voltage. Consequently, five variables were fitted, namely dinterface, $\mathrm{f}_{\mathrm{MgO}}, \mathrm{d}_{\mathrm{MgO}}, \mathrm{d}_{\mathrm{Mg}(\mathrm{OH}) 2}$, and $\mathrm{f}_{\mathrm{Mg}(\mathrm{OH}) 2 \text {. }}$

The calculated angles $(\Psi(\lambda), \Delta(\lambda))$ values well match the experimental ones as proven by the low $\chi^{2}$ values less than or equal to 1 (Fig.3, second right axis, as discussed thereafter), indicating that the optical model is adequate to describe the structure of the anodized film over the full covered voltage range.

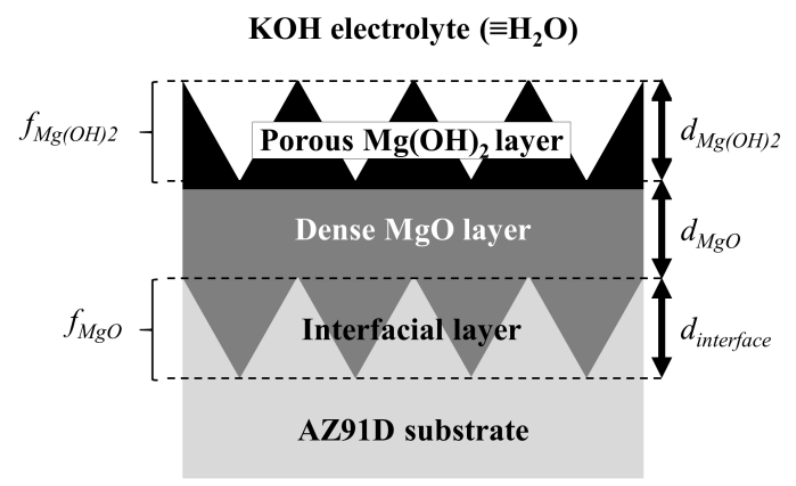

FIG. 2. Optical model used along the anodization of AZ91D alloy in KOH $3 \mathrm{M}$ at 0.1 V.s ${ }^{-1}$. Fitted variables consist of thicknesses $(d)$ and volume fractions $(f)$. Dielectric functions were all fixed and come from literature $\left(\mathrm{MgO}, \operatorname{Mg}(\mathrm{OH})_{2}\right.$, electrolyte) or are experimentally predetermined (AZ91D).

\section{IV.RESULTS AND DISCUSSION}

\section{A. Preliminary analysis of the reflected light intensity}

Figure 3 shows the reflected light intensity (left axis) simultaneously recorded to the potentiodynamic curve (first right axis) obtained for Mg AZ91D alloy in pure $3 \mathrm{M}$ 
$\mathrm{KOH}$ electrolyte. For the sake of brevity only one wavelength $(600 \mathrm{~nm})$ is shown for the optical signal. For applied voltages of up to $4 \mathrm{~V}$ current density values of $0.2-0.3 \mathrm{~mA} . \mathrm{cm}^{-}$ 2 are observed (first passive state), whereas ten times higher ones are noticed when the voltage comes to $15 \mathrm{~V}$ (second passive state). The key region is between these two passive states named here as breakthrough. The optical signal is therein disturbed, dropping to $20 \%$ but it goes up to a final plateau, with a relative high reflective intensity superior to $50 \%$. Consequently, concerning the optical data, the signal-to-noise ratio remains high and the overall level of confidence is considered as high enough. As a fit quality criterion, the $\chi^{2}$ values also depicted in Fig.3 (second right axis) are found low.

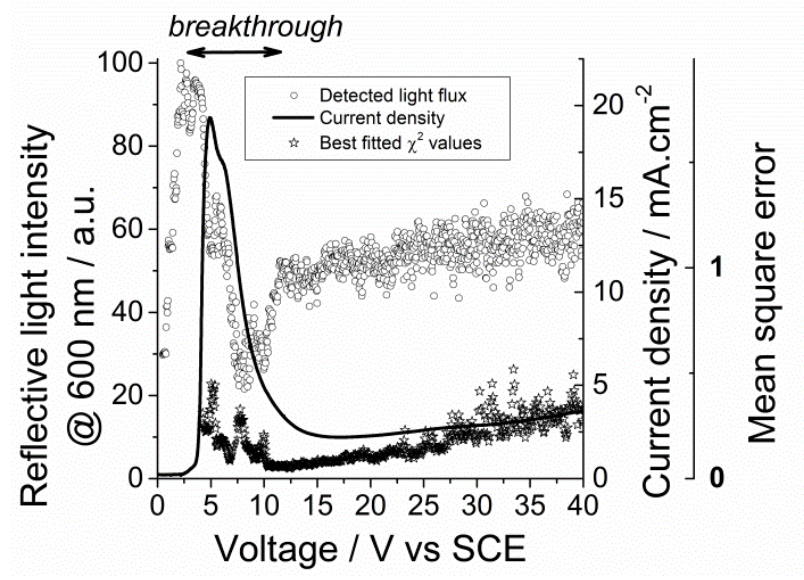

FIG. 3. Variation of the reflected intensity of the beam light at $600 \mathrm{~nm}$ (open circle symbols, left axis) during the potentiodynamic scan (bold line, first right axis) of the

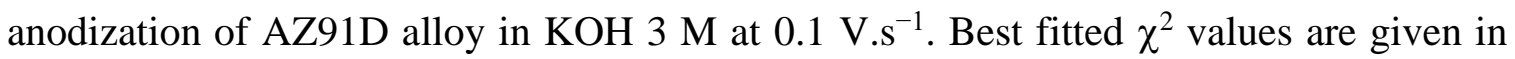
the second right axis. 


\section{B. Analysis of the anodization process}

Figure 4 shows the morphological properties determined by ellipsometry. From 0 to $4 \mathrm{~V}$, the previous in situ monitoring experiments ${ }^{12}$ have shown that a pure and compact $\mathrm{MgO}$ layer linearly increases. Above $4 \mathrm{~V}$, this work demonstrates that the film has to be considered as triplex according to the model of the figure 3 . Indeed the corresponding the $\chi^{2}$ values are inferior to 0.5 proving the suitability of the optical interface model. 


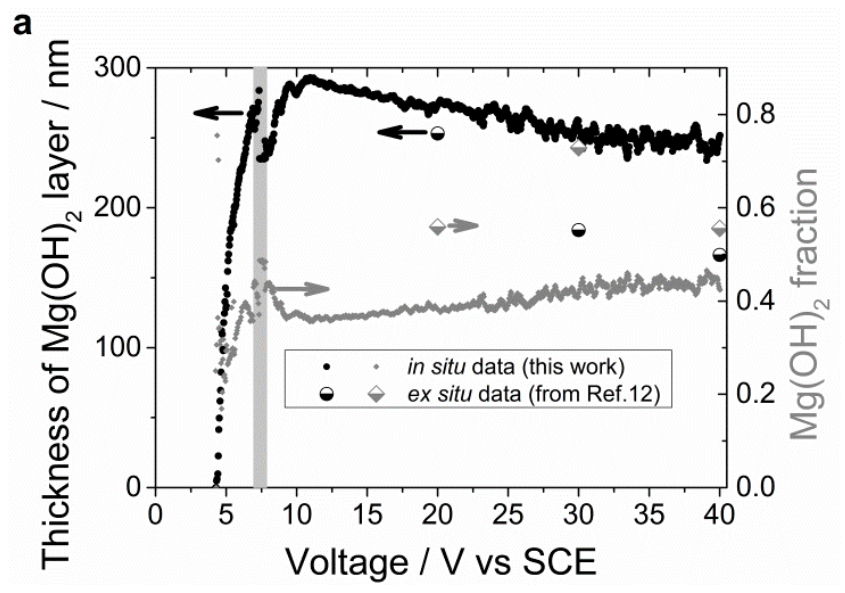

b
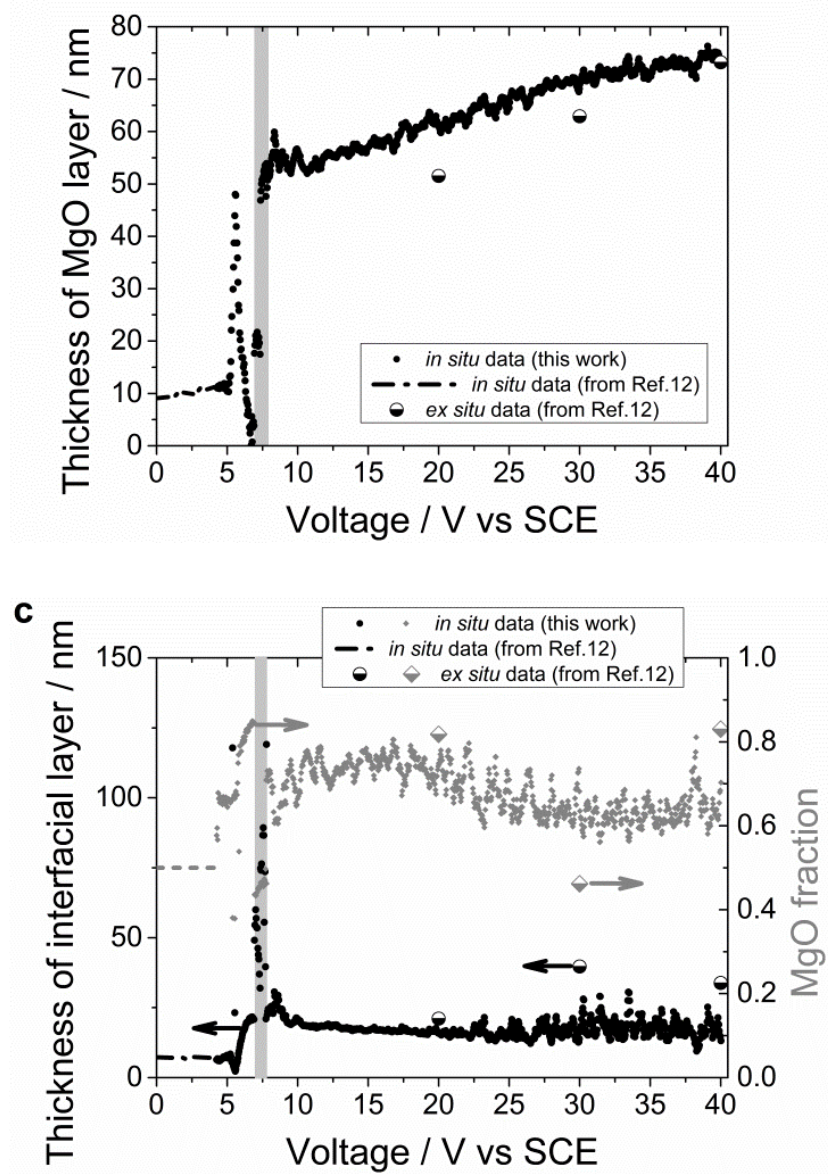

FIG. 4. Best fitted variables monitored by SE of (a) external $\mathrm{Mg}(\mathrm{OH})_{2}$ layer (b) inner $\mathrm{MgO}$ layer and (c) interfacial layer. $\mathrm{f}_{\mathrm{MgO}}$ is fixed in the 0-4 $\mathrm{V}$ range (dashed line). The 
grayed area corresponds to the voltage range where optical model errors introduced artifacts in the fitted parameters.

From 4 to $7 \mathrm{~V}$, the upper magnesium hydroxide reaches a thickness of $c a .300 \mathrm{~nm}$ (Fig. 4a, left axis). Its porosity is important as indicated by the $\mathrm{f}_{\mathrm{MgOH} 2}$ values (Fig. 4a, right axis). In the meantime, under this membrane, both $\mathrm{MgO}$ dense and interfacial layer vary significantly. The dense oxide layer sharply grows up to $50 \mathrm{~nm}$ at $5.5 \mathrm{~V}$ (Fig.4b), meanwhile the interfacial layer decreases abruptly. From 5.5 to $7 \mathrm{~V}$ the dense $\mathrm{MgO}$ layer in turn dramatically vanishes, before going up again towards a final repassivation. This evolution highlights the partial exposure of the base substrate. The second and final passive state at $7 \mathrm{~V}$ consecutive to the breakthrough occurrence consists of a rougher interfacial layer $(\sim 25 \mathrm{~nm})$ and a thicker dense oxide layer $(\sim 50 \mathrm{~nm})$. The repassivation starts under the outer membrane: a net uptake of dense $\mathrm{MgO}$ component in the $\mathrm{Mg}(\mathrm{OH})_{2} / \mathrm{MgO} /$ interface is rapidly raised from 7 to $8 \mathrm{~V}$ i.e. $\sim 35 \mathrm{~nm} . \mathrm{V}^{-1}$ assuming a linear evolution. In addition to the oxide growth, the water oxidation at the interface is still promoted, interfering somewhat with the reflected light beam which intensity passes through a minimum in this area (Fig. 3). From $10 \mathrm{~V}$ the second passive state evolves slightly up to $40 \mathrm{~V}$. Concerning the $\mathrm{MgO}$ layer, its thickness goes from 55 to $74 \mathrm{~nm}$. By taking into account its effective thickness (See supplementary material 2 at [URL will be inserted by AIP Publishing]) i.e. from 69 to $83 \mathrm{~nm}$, a second wide linear growth regime of $0.7 \mathrm{~nm} . \mathrm{V}^{-1}$ is highlighted and therefore refining the previous rougher estimation. ${ }^{12}$ The $\mathrm{Mg}(\mathrm{OH})_{2}$ layer is becoming denser (Fig. 4) with a nearly constant effective thickness of $106 \mathrm{~nm}$ (See supplementary material 2 at [URL will be inserted by AIP Publishing]). These observations are in good agreement with the hypothesis of anodization mechanism 
governed by stress-induced $\mathrm{MgO}$ cracking and $\mathrm{Mg}(\mathrm{OH})_{2}$ precipitation process. These results finely confirm the protective role of the outer layer limiting the dissolution of the underlying $\mathrm{MgO}$ layer.

\section{CONCLUSIONS}

Among other techniques, SE participates as an analytical tool to diagnose solidliquid interfaces during wet processes and helps understanding the electrochemical processes. Probing such complex electrode/electrolyte interfaces is sometimes turmoil due to side reactions producing gas species impinging the reflected light beam in a manner that data are inoperative or just missing. This article has presented a setup arrangement combining a real time ellipsometer, an electrochemical coupling cell and a super continuum white laser to get a significant increase of the out-coming light in such depreciated monitoring conditions. The proposed setup was applied successfully to monitor the case of the pre-sparking anodization of a piece of magnesium alloy AZ91D by finely revealing the morphological characteristics of its multilayered structure. The consolidation of such in situ SE methodology with the use of a white laser is highlighted to be a convenient method for probing liquid processes that are traditionally excluded from the full extent of SE.

\section{ACKNOWLEDGMENTS}

Thanks to José Manuel Lopez (Université de Lorraine) for the fabrication of the coupling cell. Ellipsometric data were acquired at the Ellipsometry core facility of LCP-A2MC, Université de Lorraine - http://lcp-a2mc.univ-lorraine.fr. 
${ }^{1}$ K. Hingerl, in Ellipsom. Nanoscale, Springer (Losurdo, M., Hingerl, K., Berlin Heidelberg, 2013), pp. 493-527.

${ }^{2}$ T. Ohtsuka and K. Fushimi, Electrochemistry 84, 826 (2016).

${ }^{3}$ L. Berlouis, D. Mamman, and I. Azpuru, Surf. Sci. 408, 173 (1998).

${ }^{4}$ S. Böhm, R. Greef, H. McMurray, S. Powell, and D. Worsley, J. Electrochem. Soc. 147, 3286 (2000).

${ }^{5}$ N. Stein, G. Bourguignon, L. Raboin, L. Broch, L. Johann, and E. Rocca, Thin Solid Films 455-456, 735 (2004).

${ }^{6}$ Z. Lu and D.D. Macdonald, Electrochimica Acta 53, 7696 (2008).

${ }^{7}$ Y. Chen and A. Erbe, Surf. Sci. 607, 39 (2013).

${ }^{8}$ P. Laha, M. Nazarkin, A. Volkova, M. Simunin, H. Terryn, S. Gavrilov, and J. Ustarroz, Appl. Phys. Lett. 106, 101904 (2015).

${ }^{9}$ Y. Takabatake, Y. Kitagawa, T. Nakanishi, Y. Hasegawa, and K. Fushimi, J. Electrochem. Soc. 164, C349 (2017).

${ }^{10}$ D.D. Macdonald, Russ. J. Electrochem. 48, 235 (2012).

${ }^{11}$ J.D. Sloppy, D.D. Macdonald, and E.C. Dickey, J. Electrochem. Soc. 157, C157 (2010).

${ }^{12}$ A. Zimmer, D. Veys-Renaux, L. Broch, N. Stein, and E. Rocca, J. Electrochem. Soc. 164, C1059 (2017).

${ }^{13}$ C. Barchiche, D. Veys-Renaux, and E. Rocca, Surf. Coat. Technol. 205, 4243 (2011).

${ }^{14}$ D. Veys-Renaux, E. Rocca, and G. Henrion, Electrochem. Commun. 31, 42 (2013).

${ }^{15}$ D. Veys-Renaux, E. Rocca, J. Martin, and G. Henrion, Electrochimica Acta 124, 36 (2014).

${ }^{16}$ E. Rocca, D. Veys-Renaux, and K. Guessoum, J. Electroanal. Chem. 754, 125 (2015).

${ }^{17}$ D. Veys-Renaux and E. Rocca, J. Solid State Electrochem. 19, 3121 (2015).

${ }^{18}$ A. Yerokhin, X. Nie, A. Leyland, A. Matthews, and S. Dowey, Surf. Coat. Technol. 122, 73 (1999). 
${ }^{19}$ J. Yahalom and J. Zahavi, Electrochimica Acta 16, 603 (1971).

${ }^{20}$ S. Ikonopisov, Electrochimica Acta 22, 1077 (1977).

${ }^{21}$ M. Miyamoto, M. Yamamoto, T. Akiyama, N. Yoshida, M. Tokitani, and A. Sagara, Nucl. Mater. Energy 9, 132 (2016).

${ }^{22}$ L. Broch, N. Stein, A. Zimmer, Y. Battie, and A.E. Naciri, Thin Solid Films 571, 509 (2014).

${ }^{23}$ J. Chen and Q. Zhan, in Handb. Adv. Non-Destr. Eval., Springer (Ida N., Meyendorf N., Cham, 2018), pp. 1-29.

${ }^{24}$ D.M. Roessler and D.R. Huffman, in Handb. Opt. Constants Solids II, Academic Press (Palik, E.D., Orlando, Florida, 1991), pp. 919-955.

${ }^{25}$ A. Pishtshev, S.Z. Karazhanov, and M. Klopov, Comput. Mater. Sci. 95, 693 (2014).

${ }^{26}$ M.R. Querry, D.M. Wieliczka, and D.J. Segelstein, in Handb. Opt. Constants Solids II, Academic Press (Palik, E.D., Orlando, Florida, 1991), pp. 1059-1078.

${ }^{27}$ S.D. Cramer and B.S. Covino, Corrosion: Fundamentals, Testing and Protection (ASM international, 2003). 
Figure captions

FIG. 1. Top-view scheme of the coupling flow cell used for the electrochemical anodization at high voltage in $\mathrm{KOH}$ electrolyte in a three electrodes configuration: the working electrode (a), the counter electrode (b) and the reference electrode (c). Visible supercontinuum laser beam enters and leaves the cell through quartz windows (d). Electrolyte circulation enters and leaves the cell through inlet and outlet (e).

FIG. 2. Optical model used along the anodization of AZ91D alloy in $\mathrm{KOH} 3 \mathrm{M}$ at 0.1 V.s ${ }^{-1}$. Fitted variables consist of thicknesses (d) and volume fractions (f). Dielectric functions were all fixed and come from literature $(\mathrm{MgO}, \mathrm{Mg}(\mathrm{OH}) 2$, electrolyte) or are experimentally predetermined (AZ91D).

FIG. 3. Variation of the reflected intensity of the beam light at $600 \mathrm{~nm}$ (open circle symbols, left axis) during the potentiodynamic scan (bold line, first right axis) of the anodization of AZ91D alloy in $\mathrm{KOH} 3 \mathrm{M}$ at $0.1 \mathrm{~V} . \mathrm{s}^{-1}$. Best fitted $\chi^{2}$ values are given in the second right axis.

FIG. 4. Best fitted variables monitored by SE of (a) external $\mathrm{Mg}(\mathrm{OH})_{2}$ layer (b) inner $\mathrm{MgO}$ layer and (c) interfacial layer. $\mathrm{f}_{\mathrm{MgO}}$ is fixed in the $0-4 \mathrm{~V}$ range (dashed line). The grayed area corresponds to the voltage range where optical model errors introduced artifacts in the fitted parameters. 


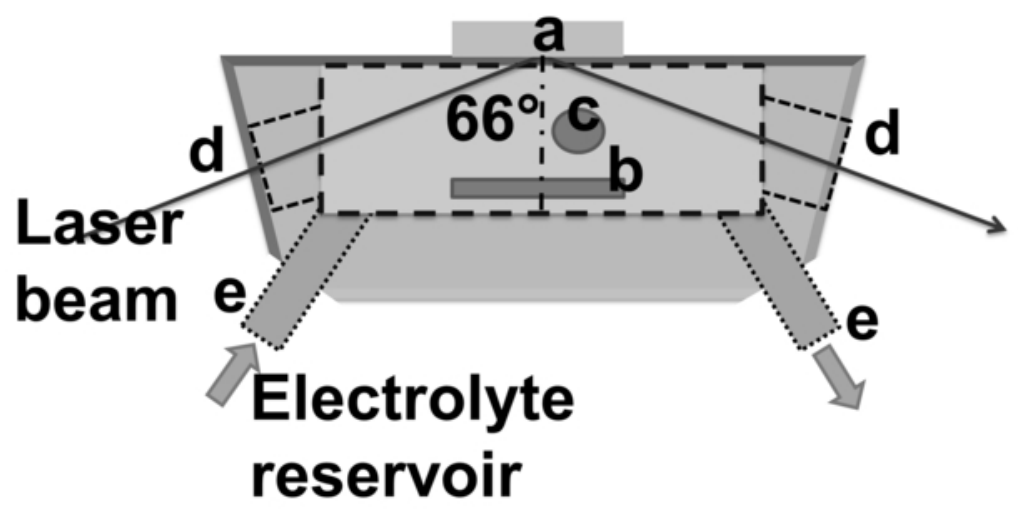


KOH electrolyte $\left(\equiv \mathrm{H}_{2} \mathrm{O}\right)$

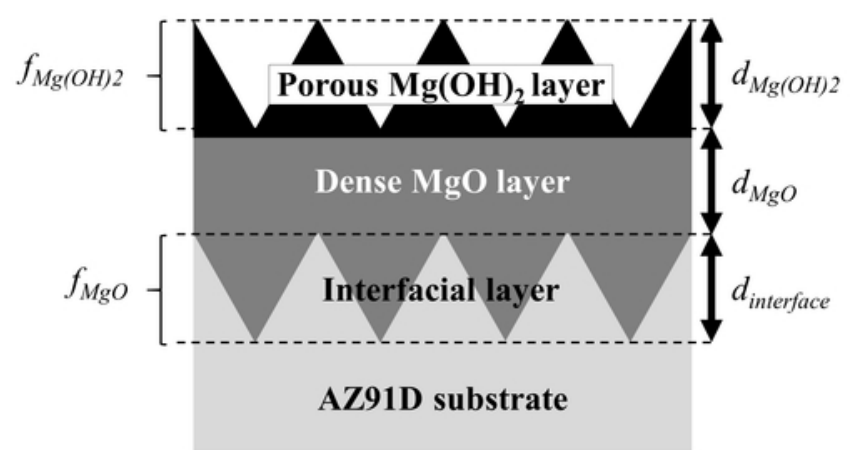




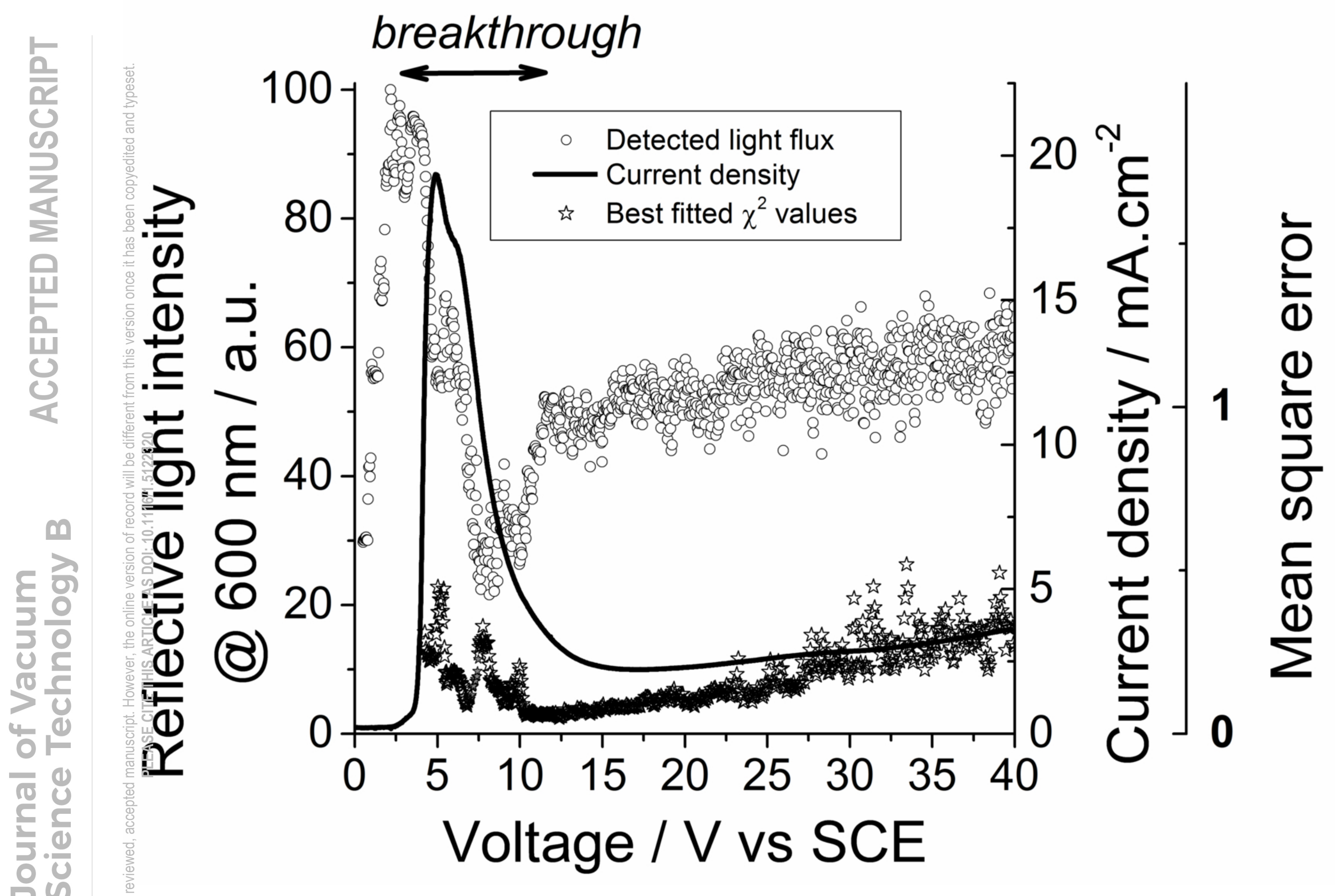


a

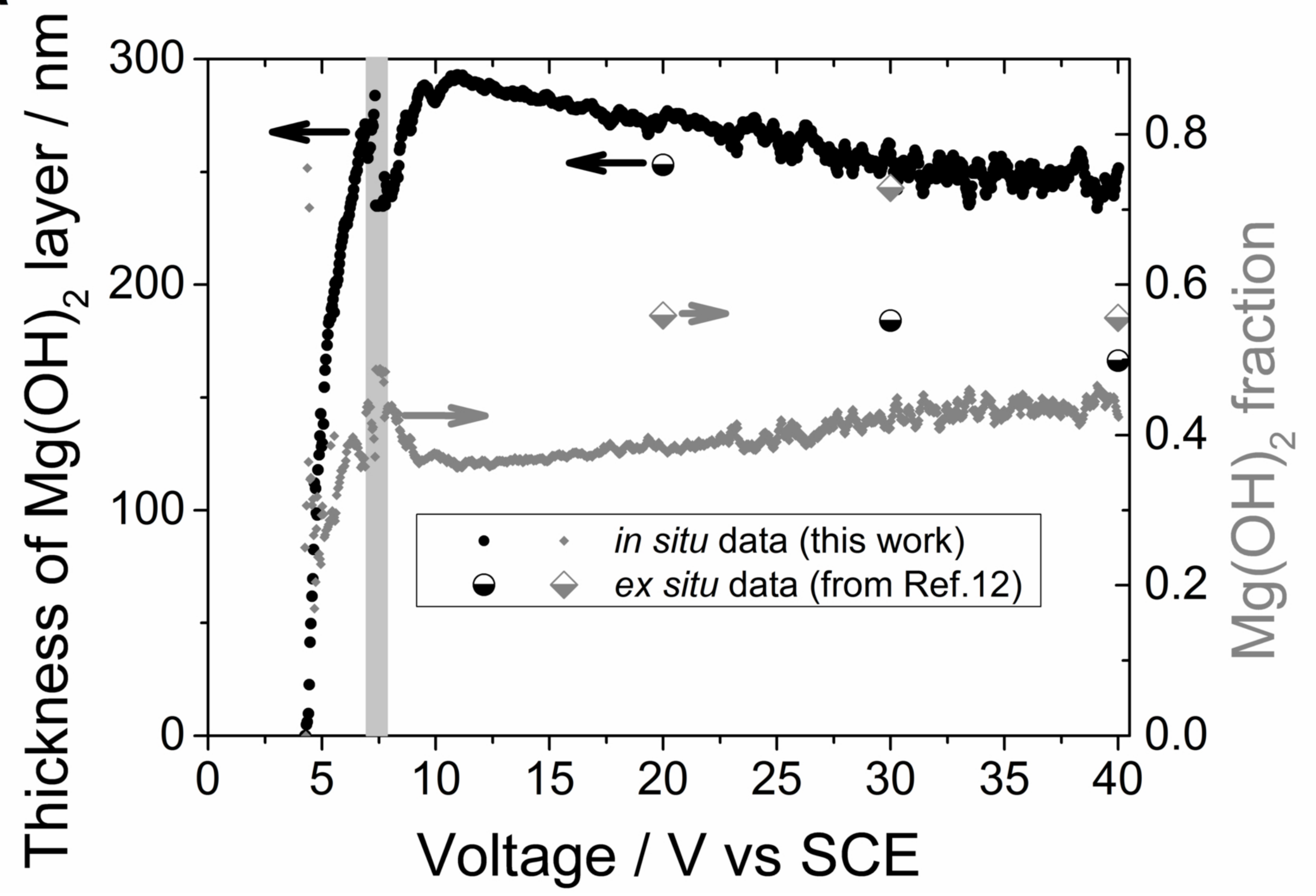




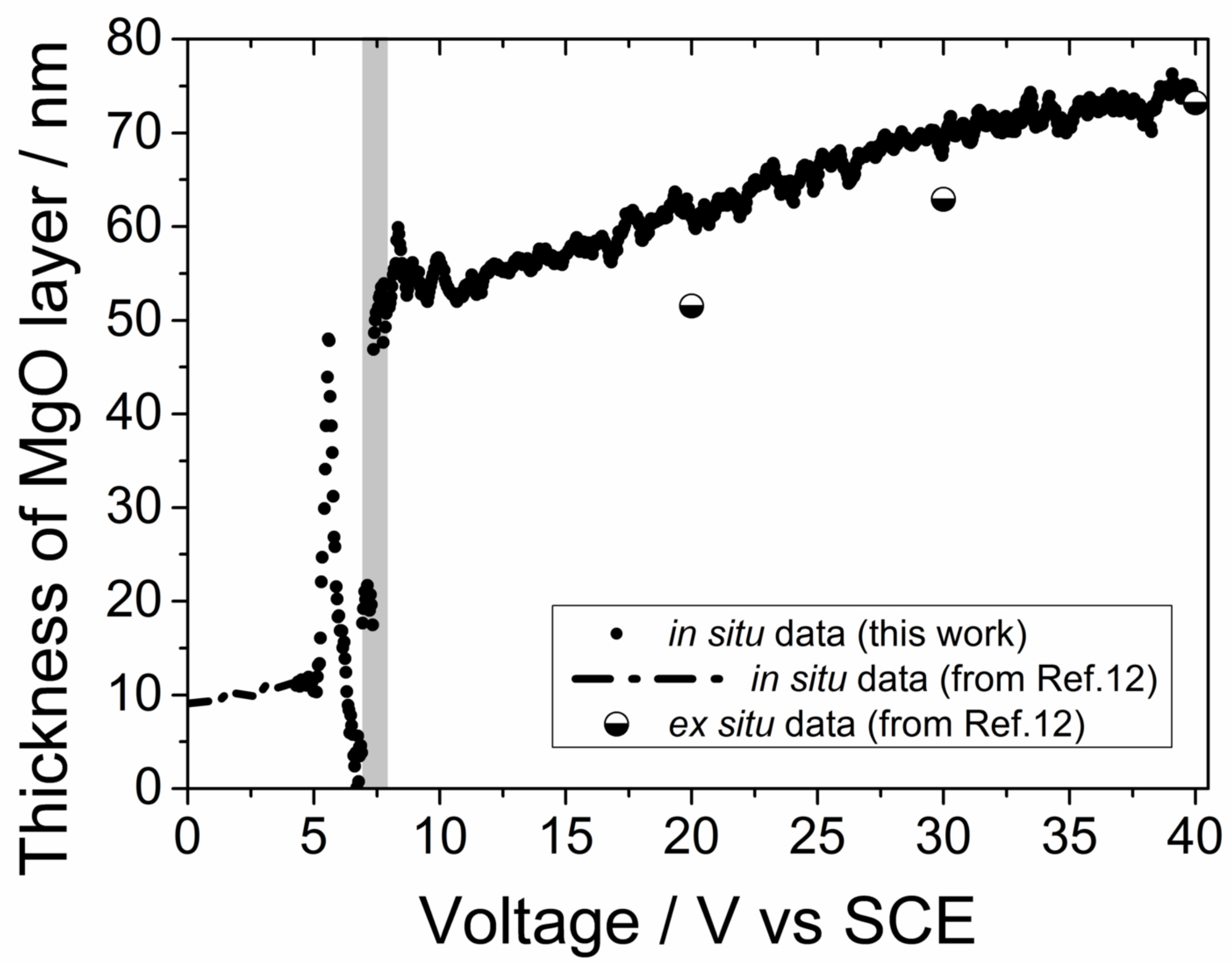




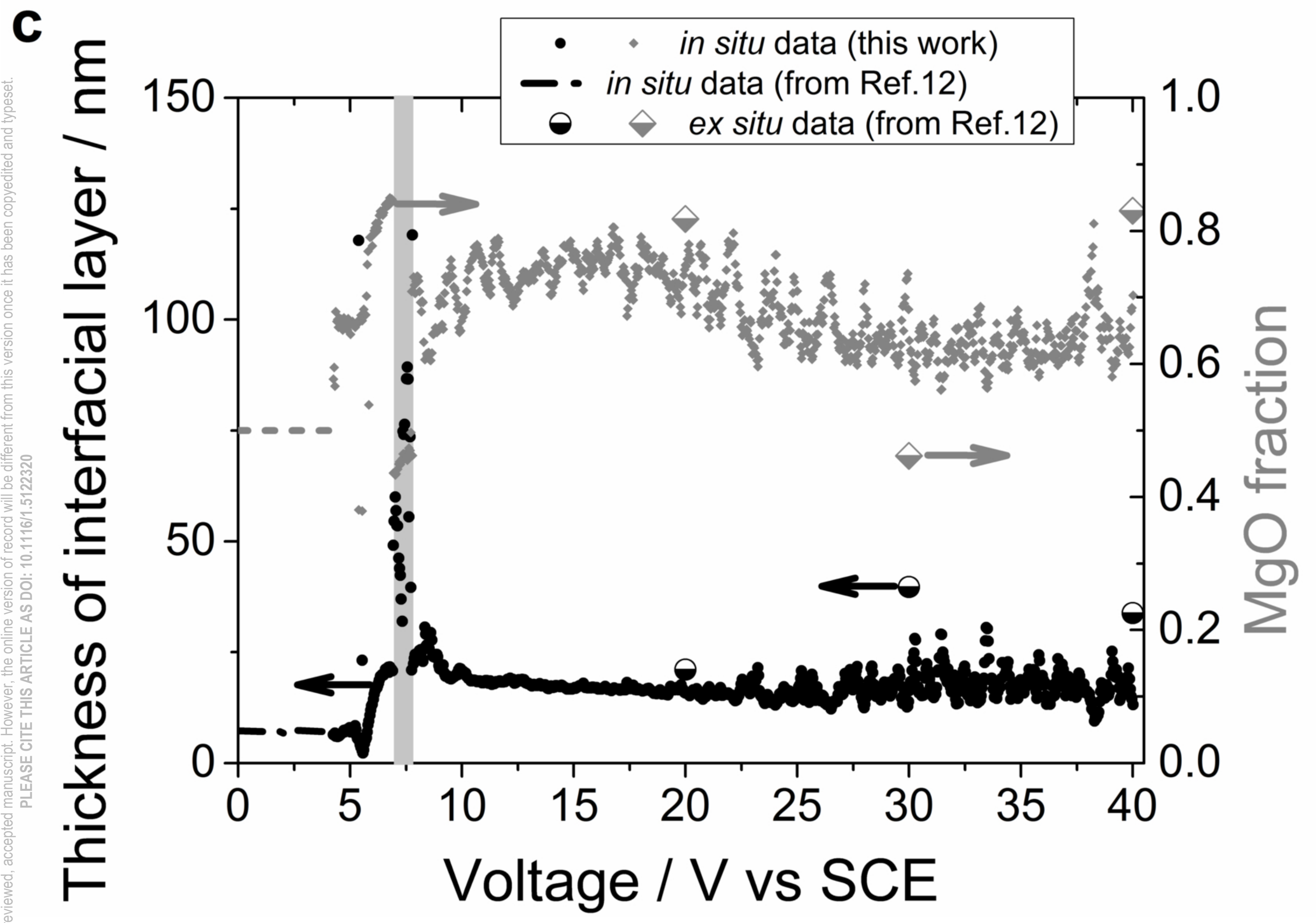

